\title{
Development of an Observational Instrument to Assess Gastro- Esophageal Reflux Disease in Premature Infants
}

\author{
Christina Sandberg ${ }^{1}$ and Susanne Georgsson Öhman ${ }^{2, *}$
}

\author{
${ }^{1}$ Neonatal Unit, Astrid Lindgrens Children's Hospital, Danderyd Karolinska University Hospital, Sweden \\ ${ }^{2}$ Department of Women's and Children's Health, Karolinska Institutet, Sophiahemmet University, Sweden
}

\begin{abstract}
Background: Premature infants are at increased risk of developing Gastroesophageal Reflux Disease (GERD), which for these children is associated with a number of severe symptoms. There is great need for effective instruments and clear symptom criteria to assess the presence and degree of severity of GERD.

Aim: To develop and pilot test an observation instrument for early detection of symptoms of GERD in premature infants.

Method: A combination of three research methods was used - systematic literature review, observation instrument development and a pilot test.

Results: The systematic review identified specific symptoms of GERD. The development of the observational instrument started with the establishment of concordance between the criteria of symptoms according to the literature review and to NIDCAP, "Newborn Individualized Developmental Care and Assessment Program". In the pilot test the criteria of symptoms were revised by comparing the result and the criteria between infants that clinically were estimated to have had a reflux problem and the ones who did not.

Conclusion: An observation instrument was developed. The clinical evaluation by a pilot test showed that the instrument could be useful to record significant symptoms and combinations of symptoms that may occur in premature infants assessed as having reflux problems.
\end{abstract}

Keywords: Premature infants, GERD symptoms, and observation instruments.

\section{INTRODUCTION}

Premature infants are at increased risk of developing Gastroesophageal Reflux Disease, GERD, which for these children [1, 2] as well as for full-term infants [3] is associated with a number of severe symptoms. According to a critical review by Poets, no objective symptom criteria exist to identify those premature infants or other children who have GERD and who require treatment [4].

Infants with GERD show an increased incidence of reflux episodes. Fifty percent have delayed gastric emptying and increased pressure in the abdomen. Other factors such as various drugs and dietary habits are also important [5]. Physiological gastroesophageal reflux, GER, is found in most infants but disappears during the first year of life when the tone of the LES (Low Esophageal Sphincter) has matured [6-8]. GERD in infants is often characterized by symptoms from the gastrointestinal canal and the respiratory organ. Throat and feeding problems lead to poor weight gain and respiratory problems, which for some infants become permanent [9]. Infants with symptoms often show general signs of discomfort such as irritability and inconsolable crying $[1,3,10,11]$. GERD is a pathological process and, due to the acidic gastric juice effect on

*Address correspondence to this author at the Box 5605, SE-114 86 Stockholm, Sweden; Tel: +46700017344; E-mail: susanneoh@shh.se mucous membranes and associated respiratory complications, causes damage and problems such as esophagit, pneumonia, and apnea-tendencies [11-15]. Current treatment strategies are medical and nursing care, which includes the positioning of the body, different eating strategies, medical and surgical care $[11,14,16,17]$. It is important for nurses to assess the food intake situation and see how the parents handle this and in what position they hold the baby right after the meal, because that is when reflux symptoms often occur [7]. Registration, observation and documentation of these infant's symptoms records how they respond to therapy [15]. Nursing plays a major role in contributing to a correct diagnosis and treatment and in supporting parents by providing information, advice and support $[7,18,19]$. Nurses in the neonatal and pediatric care services have an important task to recognize an infant at risk of developing GERD, which is of great importance for being able to deal with the problem in an adequate way $[15,16]$. Today, some diagnostic tools exist which attempt to distinguish between physiological and pathological GER, i.e. GERD $[20,21]$. For premature infants there is a lack of clear indicators of symptoms that by medical and nursing staff easily and accurately measure the incidence and severity of GERD. Questionnaires need to be diagnostic and able to identify the presence or absence of disease. There are no effective questionnaires or tools for trained staff to systematically with objective criteria assess 
symptoms of GERD for younger groups of infants $[1,4,22]$. Objective criteria that help to identify those presumably few infants who do require treatment for GERD are urgently needed [4]. Few measurement instruments are described in the literature for establishing the diagnosis of GERD in infants and young children $[1,3,22]$.

We hypothesized that it is possible to detect symptoms by a clinical systematic observation according to an instrument which can facilitate the diagnosis of GERD.

\section{AIM}

The aim of this work was to develop and pilot test an observation instrument for early detection of symptoms of GERD in premature infants.

\section{METHOD}

A combination of three research methods was used to develop and test an observation instrument to be used for the detection of GERD in premature infants 1) Systematic review, 2) Development of the observation instrument, 3) Pilot testing of the observation instrument.

\section{1) Systematic Review of the Literature to Support Inclusion of Items}

A systematic review was performed to delineate the underlying mechanisms of premature infants behavior when having reflux symptoms and the age at which the pathological pattern of GERD can be distinguished from the immature behavior according to Martin et al. [23]. The review was performed according to the PRISMA (Preferred Reporting Items for Systematic reviews and Meta-Analyses) statement, using part of the 27-item checklist for transparent reporting of a systematic review [24].

\section{Implementation and Data Collection}

The aim of this phase was to collect data from studies that were reliable, valid and free from bias. Keywords were defined and criteria specified for which the studies would be selected [25-27]. Articles regarding the symptoms, the relevant parameters of GERD in premature infants were searched and compiled systematically to delineate specific symptoms, symptom variation during the course of the day and the age of the premature infant where the pattern of GERD can be distinguished from behaviors due to the immature state. Relevant articles were only found in the databases PubMed. Of 155 identified articles, 19 were included. Identification of specific symptom criteria and behaviors of GERD was searched for in the articles. Dimilarities and differences in the findings were analyzed and conclusions were compiled $[25,27]$.

\section{2) Development of the Observation Instrument}

\section{Implementation}

The specific symptoms of GERD resulting from the systematic review were compared with the symptoms that described the infant's behavior and development according to NIDCAP, "Newborn Individualized Developmental Care and Assessment Program", a procedure suggested by De Groot et al. [28]. Based on this comparison a category system was constructed to classify the observed symptoms, using the "structured observation of NIDCAP" as a prototype [29]. An observation form was constructed to record the observed phenomena. The developed instrument was then evaluated by using a pilot test.

\section{Structured Observation of NIDCAP}

NIDCAP, is a philosophy of care that dominates the neonatal care in most neonatal units in Sweden. It is both an observation method and a nursing program to provide premature infants with individualized neonatal care. It is based on that the infant's behavior is the main way to show their stress thresholds, stability and wellbeing. An observation comprises the registration of the infant's behavior related to medical and/or caring actions [30].

\section{3) Pilot Test of the Observation Instrument}

The pilot test was expected to provide answers on how the observational instrument would work in practical use [31]. The study was aimed to test the usefulness of the instrument in a clinical setting and to be a starting point to go further and test the instrument in a larger extent. A total of 14 preterm infants and parents were included in the pilot test. Eight of the infants who participated had problems with "spitting up" and seemed to be bothered by this, while some others had unclear desaturation. Another six infants who had not demonstrated any particular problems were observed in order to be able to compare any difference in symptom registration. The form was revised four times and a total of 18 training observations were made on the 14 premature infants. The first version was tested during eight observations on four infants, and then the criteria and categories were reconsidered. 
Table 1: Reflux Disorders and Medical Treatment - Pilot Test of 14 Children

\begin{tabular}{|c|c|c|c|c|c|c|}
\hline \multirow{2}{*}{$\begin{array}{l}\text { Child } \\
\text { no. }\end{array}$} & \multirow[t]{2}{*}{ Gw at birth } & \multicolumn{3}{|c|}{ Reflux disorders } & \multirow{2}{*}{$\begin{array}{c}\text { Medical treatment } \\
\qquad \mathrm{X}=\text { Yes }\end{array}$} & \multirow{2}{*}{$\begin{array}{c}\text { Effect of medical } \\
\text { treatment }\end{array}$} \\
\hline & & None & Diffuse & Pronounced & & \\
\hline 1 & $25+1$ & & & $x$ & $x$ & Good \\
\hline 2 & $29+5$ & & & $x$ & $x$ & Good \\
\hline 3 & $27+6$ & & & $x$ & $x$ & Uncertain* \\
\hline 4 & $25+3$ & & & $x$ & & \\
\hline 5 & $29+1$ & & & $x$ & & \\
\hline 6 & $26+3$ & & & $x$ & $x$ & Good \\
\hline 7 & $30+5$ & & $x$ & & & \\
\hline 8 & $32+1$ & & $x$ & & & \\
\hline 9 & $31+2$ & $x$ & & & & \\
\hline 10 & $28+6$ & $x$ & & & & \\
\hline 11 & $31+4$ & $x$ & & & & \\
\hline 12 & $31+2$ & & & $x$ & & \\
\hline 13 & $33+5$ & $x$ & & & & \\
\hline 14 & $31+1$ & & & $x$ & $x$ & Good \\
\hline
\end{tabular}

*The baby had bowel and urinary tract malformations

This was performed by comparing the results and criteria between the infants who were judged clinically to have had reflux symptoms and needed medical treatment and those who did not (Table 1).

\section{ETHICAL CONSIDERATIONS}

Parents were informed verbally about the research project and what their participation would entail. Parents gave verbal and written consent. The Ethics Committee at Karolinska Institutet approved the study. Dnr: 2008/282-31/2

\section{RESULTS}

\section{1) Systematic Review of the Literature to Support Inclusion of Items}

\section{Specific Symptoms of GERD in Premature Infants}

The most common symptoms of GERD were: apnea, bradycardia, desaturation, frequent regurgitation, "gagging", chewing, vomiting, low food intake, difficulties with eating, some intolerance of food and difficulty gaining weight/failure to thrive [32-36]. Other frequently documented symptoms of GERD were: coughing, "grunting" (labored breathing), recurrent attacks with cyanosis, arching, grimacing, crying, showing signs of irritability, discomfort and pain, and stretching out extremities [37-40]. Other studies describe some of these symptoms as not so common/more rare, like difficulty gaining weight/failure to thrive, desaturation, "choking", "gagging", chewing, refusing to eat, irritability, showing discomfort, grimacing, and arching, cough, yawning, hiccups and sneezing $[41,42]$. Some studies stated that GERD and premature apnea is common in premature infants and seem to be timely related to each other, which would mean that occasions of reflux can trigger apnea in premature infants [43-45]. Other studies describe both apnea, bradycardia, desaturations and GERD are common in premature infants, but with few exceptions, there is no evidence for a fixed relationship between them $[46,47]$. In that case reflux-specific behavioral criteria may not be suitable as diagnostic criteria for GERD in premature infants. In one study, the assessment of reflux-specific behavioral patterns did not differ significantly in the presence or non-presence of acid reflux in healthy premature infants [42]. Another study showed, however, that clinical signs such as vomiting, regurgitation, "arching", cough, irritability, etc. may be more useful for the presumptive diagnosis of GERD in premature infants than invasive examinations [48].

\section{The Age of the Premature Child when the Pattern of GERD can be Distinguished}

In healthy premature infants, with a gestational age of 31-38 weeks, TLESRs (Transient Low Esophageal 
Sphincter Relaxation), are the leading cause of GERD $[42,49]$. GERD is considered common in premature infants younger than 34 weeks gestational age, but the severity of GERD is not significantly different in symptomatic and asymptomatic infants $[37,40,50]$. Some authors stated that GERD is common even in premature infants younger than 32 weeks gestational age $[33,34,36,41,44]$. Infants with recurrent apnea have been studied at different ages, where gestational age at birth varied between 24-36 weeks and the studies have been conducted when the infants were 7-32 days old [32,43,46-48].

\section{Symptom Variation During the Course of the Day}

According to some studies, premature infants showed symptoms of GERD in terms of increased frequency of regurgitation, desaturation, apnea and bradycardia after meals $[34,44]$. Other studies argue that a greater number of reflux episodes per hour occur during mealtime, compared to the fasting period [50]. One study showed that reflux episodes are most common between 120 and 150 minutes after a meal [33]. This would imply that an appropriate time of the day to observe an infant with symptoms of GERD is during and after meals.

\section{2) Development of the Observation Instrument}

The development of the observation instrument followed the processes rooted in the methodology literature $[28,29]$. Specific symptoms, identified in the systematic review, were compared with symptoms describing the infant's behavior and development according to NIDCAP. From consensus concerning relevant symptoms a category system was constructed to classify and group the observed symptoms with the "structured observation of NIDCAP" as a model. The category system formed the basis for the design of an observation form that in a systematic way could record observed symptom criteria.

\section{Symptoms that Describe the Child's Behavior and Development of the NIDCAP}

The NIDCAP model has a clear nursing focus since behavioral observations lead to individual nursing actions. The model is used to register and interpret the infant's behavior from five different subsystems: autonomic/physiological system; motor system; wakefulness regulatory system; the system for attention and interaction and the self-regulating system. The three main systems are the autonomic, motor and wakefulness regulatory systems [30].

\section{Consistency of the Symptom Criteria of the Systematic Literature Review and NIDCAP}

The behaviors of NIDCAP described as stress signals of the autonomic and motor systems, conform to a large extent with many of the most common symptoms of GERD, according to the above-performed systematic review (Table 2).

\section{Construction of a Category System to Classify the Observed Symptoms}

The five different subsystems in the NIDCAP-model could be compared to a system of categories, where the three main categories, are the autonomic, motor and wakefullness regulation. The following specific criteria based on symptoms, described by the systematic review, matches well with the specified symptom criteria to be recorded in a NIDCAP observation form (Table 2).

\section{Presentation of the Observation Form}

The resulting form was designed to capture the frequency of various specified symptom criteria assessed at two-minute intervals. Each form contained ten columns á two minutes for a total of 20 minutes of observation time. The symptom criteria followed a similar order as on the observation form, according to NIDCAP but without headings for the overall category

Table 2: Itemized/Specified Symptom Criteria According to Systematic Review and NIDCAP

\begin{tabular}{|c|c|c|c|c|c|c|c|c|}
\hline $\begin{array}{l}\text { Behaviors and } \\
\text { Symptoms that } \\
\text { are recorded in } \\
\text { NIDCAP. } \\
\text { observation form }\end{array}$ & $\begin{array}{l}\text { Irregular breathing } \\
\text { Breathing pauses } \\
\text { Color changes } \\
\text { Cyanosis }\end{array}$ & $\begin{array}{l}\text { Spit up } \\
\text { Gag } \\
\text { Burp } \\
\text { Gasp }\end{array}$ & $\begin{array}{l}\text { Hiccups } \\
\text { Sneeze } \\
\text { Yawn }\end{array}$ & Fuss & $\begin{array}{l}\text { Grimace } \\
\text { Tongue } \\
\text { extension }\end{array}$ & Arching & $\begin{array}{l}\text { Extending } \\
\text { extremities }\end{array}$ & $\begin{array}{l}\text { Diffuse } \\
\text { squirm } \\
\text { Frantic } \\
\text { diffuse } \\
\text { motor } \\
\text { activity }\end{array}$ \\
\hline $\begin{array}{c}\text { Specified } \\
\text { symptoms } \\
\text { criteria for GERD } \\
\text { according to the } \\
\text { systematic } \\
\text { review }\end{array}$ & $\begin{array}{c}\text { Apneas } \\
\text { Desaturations } \\
\text { Bradycardia } \\
\text { Attack of cyanosis }\end{array}$ & $\begin{array}{c}\text { Vomiting } \\
\text { Regurgitation } \\
\text { "Gagging" } \\
\text { Chewing } \\
\text { "Choking" }\end{array}$ & $\begin{array}{l}\text { Hiccups } \\
\text { Sneeze } \\
\text { Cough }\end{array}$ & Crying & $\begin{array}{l}\text { Grimace } \\
\text { Stretch out } \\
\text { ones } \\
\text { tongue }\end{array}$ & Arching & $\begin{array}{c}\text { Stretching out } \\
\text { the } \\
\text { extremities }\end{array}$ & $\begin{array}{l}\text { Show signs } \\
\text { of irritability, } \\
\text { discomfort } \\
\text { and pain }\end{array}$ \\
\hline
\end{tabular}


name. The criteria were still held together in three parts by gaps between the parts. The first section of the form includes the specified criteria symptoms, "apnea", "desaturation", "bradycardia" and "attack of cyanosis" (Table 2). These criteria were comparable with the headlines Respiration, Color, Heart rate, Respiration Rate and Saturation according to the NIDCAP form. In the developed form, the headings "Obstructive apnea", "Color changing", "Bradycardia", "Saturation" and "Oxygen required" were used. The second section of the form includes the specified criteria symptoms, "vomiting", "regurgitation", "gagging", "chewing" and "choking" (Table 2). This part did relatively well accord to the heading Visceral/respiratory according to NIDCAP form. In the developed form, the headings "Vomiting/spits up", "Regurgitations", "Gagging", "Burps", "Dysphagia-refusing to eat" and "Grimacing" were used. The third section of the form covered the specified symptom criteria, "arching", "stretching out the extremities", "crying" and "showing signs of irritability, discomfort and pain" (Table 2). The first three criteria were comparable with the NIDCAP form under the heading Motor and Attention. In the developed form, the headings "Fussiness/irritability", "Painful experiences", "Arching" and "Diffuse squirm" were used. The criteria "stretching out the extremities" and "showing signs of irritability, discomfort and pain" were not included as separate symptom headlines in preparing this form. The term "diffuse squirm" is taken directly from the NIDCAP form and is useful for capturing a behavior that expresses irritability, discomfort and pain. An appropriate time of day to observe an infant with symptoms of GERD is during and after meals, about two to two and a half hour after, and just before the next meal. This could mean that the infant can be observed at any time during the day.

\section{3) Pilot Test of the Observation Instrument}

\section{Specific Symptoms Recorded by Using the Observation Form}

The initial observation form was designed to capture the frequency of various specified symptom criteria recorded in the two-minute intervals. The symptoms criteria followed a similar order as the NIDCAP observation form but headings for the overall category names were not used. When using the first version of the form, a need of a clearer structuring of the symptom criteria was discovered and that some criteria were unnecessary and did not complete the observation as expected. The preparation of the next version followed a more distinct division of symptom criteria according to the NIDCAP categorization. The revised observation form worked well when using it in clinic regarding the classification and categorization of the specific symptom criteria. The symptoms of acid reflux were combined as one unit in the latest version. Appendix $1=$ The Observation Form.

\section{Combinations of Specific Symptoms Criteria}

When using the first version of the observation form some symptom combinations could at an early stage distinguish infants who had problems and some were thereafter clinically diagnosed GERD and put on treatment. The last observation form worked well for the registration of the various symptom criteria and the breakdown by time intervals also clearly showed the criteria that occurred simultaneously. The symptom criteria and symptom combinations that were repeatedly observed and noted in these infants were "gagging", regurgitation, "choking" or some other signs of acid regurgitation such as grimaces, diffuse squirms, coughing and / or crying. In the more severe cases and when the infant had any type of surveillance equipment, a connection between the symptoms and desaturation, color change, bradycardia and even apnea, sometimes with a short lag could be seen.

\section{Symptom Criteria Allocated to Different Categories}

$\begin{array}{ll}\text { Categories } & \begin{array}{l}\text { Symptoms Criteria } \\ \text { A Resp./Circ.(color): }\end{array} \\ & \begin{array}{l}\text { Apnea: Alarm - Bradyc., Desaturation } \\ \text { Color changes - Pale/Cyanosis } \\ \text { B Visceral: }\end{array} \\ & \begin{array}{l}\text { Spitting/Vomiting; } \\ \text { Regurgitation, Gagging, } \\ \text { Chewing, Swallowing, Choking }\end{array} \\ \text { C Face: } & \text { Grimacing } \\ \text { D Motor: } & \text { Diffuse squirm; Arching, Twitching } \\ \text { E Attention: } & \text { Crying, Fussing, Irritability } \\ \text { F Other symptoms: } & \text { Cough }\end{array}$

\section{DISCUSSION AND INTERPRETATIONS}

\section{Symptoms Revealed in the Systematic Review}

The results of the systematic review identified the most common symptoms of GERD in premature infants. Some of the studies described certain symptoms as not so common, while other studies and authors found the same symptoms of GERD to be commonly in infants. Overall, many symptoms are similarly reported as evidenced by the systematic review. The conclusion that apnea can be caused by acid reflux is a controversial issue in which different 
authors have different opinions. Some of the studies in the systematic review stated that GERD and premature apnea are common in premature infants and seem to be timely related to each other. Other studies in the review, however, consider that apnea, bradycardia, desaturation and GERD are common in premature infants, but with few exceptions there is no evidence for a fixed relationship between them [51-54].

\section{Compilation of Symptoms}

The compilation of the specific symptoms resulted in, despite some authors' in the review different approaches, outcomes that were relevant and useful for further construction of the observation instrument. According to the systematic review several of the most common symptoms might be interpreted as an expression of discomfort and pain associated with regurgitation, spitting/gagging and vomiting. This relationship is confirmed by Condino et al., who expressed that infants experience the discomfort of even a minimal regurgitation of the contents of acid reflux up into the esophagus [10].

\section{Optimal Time for Observation}

The systematic review also found conflicting information as to what time of the day it would be optimal to observe an infant with symptoms of GERD. Other literatures have also shown quite different ideas/thoughts concerning what time of the day and when in relation to meals, reflux symptoms are most common $[5,11]$. One study showed a greater number of reflux episodes per hour occur during mealtime [50] whereas another study showed that reflux episodes were most common about two hours after a meal [33]. Consequently, this implies that the observations can be made anytime during the day since the different symptom criteria used to appear both during and after meals.

\section{Age Related to the Observation}

According to the review GERD is common in premature infants younger than 34 weeks gestational age and some studies say 32 weeks. Apneas as a phenomenon, i.e. whether it is apnea of immaturity or symptoms of GERD, can be difficult to differentiate the younger an infant is. It is difficult to draw clear conclusions about the precise age when it may be appropriate to observe an infant in an attempt to diagnose GERD. A reasonable conclusion based on the above described results is probably that the observations should be made at the earliest from gestational weeks 30-32, but observations from gestational week 34 are probably more useful and reliable for drawing conclusions about the presence and absence of GERD.

\section{The Pilot Test}

The pilot test was conducted to evaluate how the constructed observation instrument worked in practice $[23,55]$. This test was a process, which involved a questioning of what symptom criteria were practically useful and those that seemed superfluous and did not fill the role that could be expected. It is of great value that the results from recordings of symptom criteria may be graded, so that the results can be used in clinical practice and contribute to the ability to confirm or rule out a diagnosis of GERD. The observation form is part of a larger ongoing research study, which involves a test of the validity of the instrument. In this study the result from the observations will be compared with $\mathrm{pH}$ and impedance measurement, clinical assessment and parental response to follow-up questionnaires up to 18 months of age to determine the prevalence of GERD. If the results from the above research study are deemed successful, the instrument could be used by nurses in the care of the premature infants as a tool to identify those infants who have GERD.

\section{Suggestion for a Grading the Severity of the Observed Phenomena}

In a number of articles panels of experts and experts in different fields examined findings from the literature and observations and then classified, grouped and graded behavior into different categories [56-58]. The increase in frequency of symptoms criteria and symptoms combinations that were repeatedly observed were "gagging", regurgitation, "choking", grimaces, diffuse squirms, coughing and / or crying. In the more severe cases and when the infant had any type of surveillance equipment, a connection between the symptoms and desaturation, color change, bradycardia and even apnea could be seen. According to the results of the review the following grades for severity are suggested:
Grading/Rating 0 occasional symptoms from category Visceral $=$ would indicate no reflux symptoms.

Grading/Rating 1 increased frequency of symptoms from category Visceral and isolated 
symptoms from the Respiratory/Circulatory(color) = indicates light reflux symptoms.

Grading/Rating 2 further increase in frequency of symptoms from category $\underline{\text { Visceral }}$ and isolated to increased frequency of individual and/or symptom at the same time from category Respiratory/Circulatory(color) = indicates more pronounced acid reflux symptoms.

This study was a development of an instrument and a pilot test aimed to clinically evaluate the usefulness of the instrument. To be able to make reliable statistic validity analyses a large study with a more extensive data collection is demanded.

\section{CONCLUSIONS}

An observation instrument was developed from a systematic review, which delineated symptom of GERD. The clinical evaluation by a pilot test showed that the instrument could be useful to record significant symptoms and combinations of symptoms that may occur in premature infants assessed as having reflux problems.

\section{APPENDIX}

Observation form Namne:

Birth date:

Date:

Before/Under/After meal

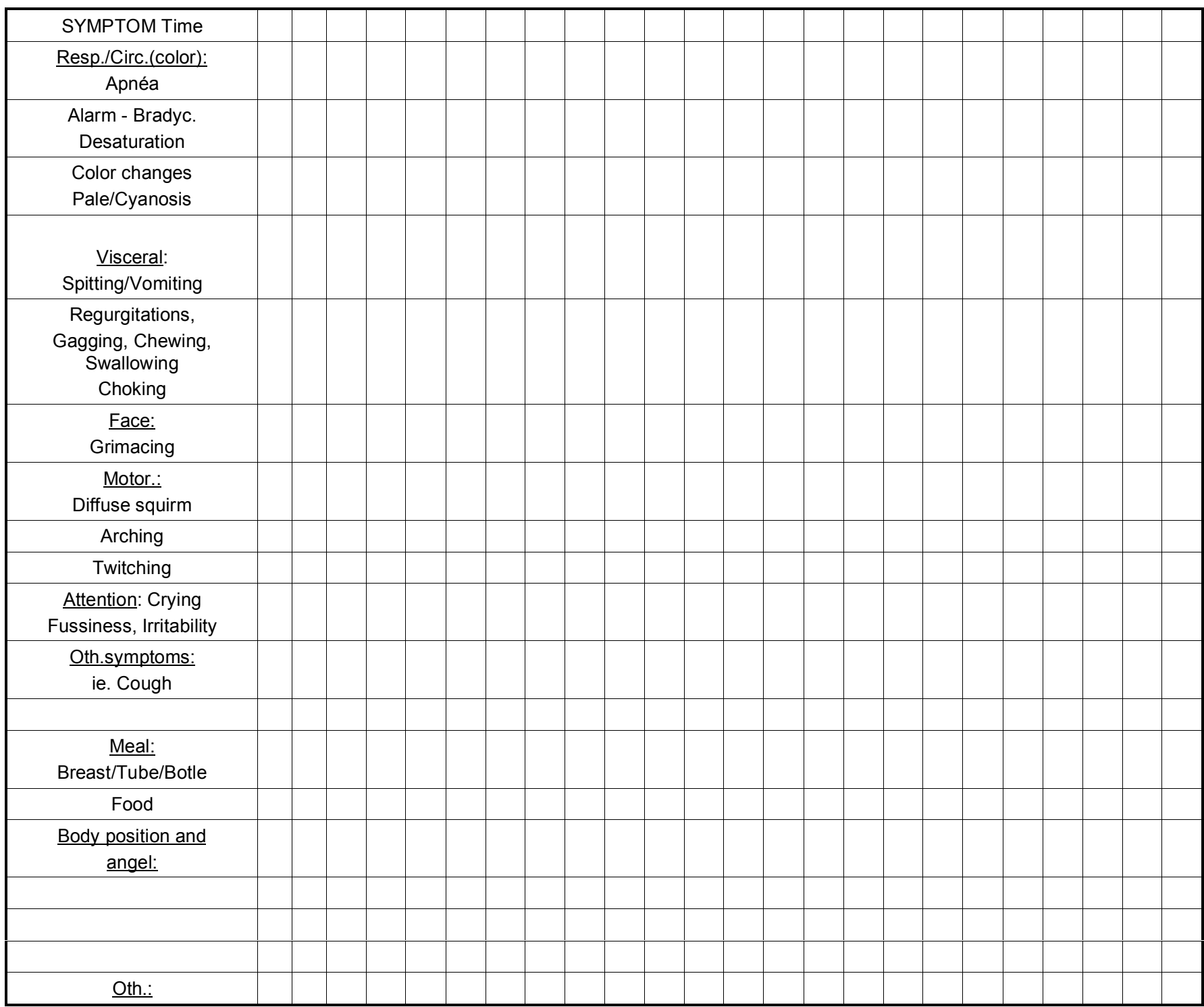




\section{REFERENCES}

[1] Kleinman L, Revicki DA, Flood E. Validation Issues in Questionnaires for Diagnosis and Monitoring of Gastroesophageal reflux Disease in Children. Current Gastroenterology Reports 2006; 8 (3): 230-6. http://dx.doi.org/10.1007/s11894-006-0080-y

[2] Tufts G. Primary Care of the Premature Infant. The American Journal for Nurse 172. Practitioner Observation Report: A Behavioral Rating Instrument for Juvenile Delinquents in Residential Care. J Clin Psychol 2004; 58 (9): 1103-17.

[3] Kleinman L, Rothman M, Strauss R, et al. The Infant Gastroesophageal Reflux Questionnaire Revised: Development and Validation as an Evaluate Instrument. Clin Gastroenterology and Hepatology 2006; 4: 588-96. http://dx.doi.org/10.1016/j.cgh.2006.02.016

[4] Poets CF. Gastroesophageal Reflux: A Critical Review of Its Role in Preterm Infants. Pediatrics 2004; 113 (2): 128-32. http://dx.doi.org/10.1542/peds.113.2.e128

[5] Cavataio F, Guandalini S. Gastroesophageal Reflux. In S. Guandalini (Eds.), Essential Pediatric Gastroenterology, Hepatology, and Nutrition. (ss.157-73). United States of America: McGraw-Hill Medical Publishing Division; 2005.

[6] Fletcher AB, Avery GB. Nutrition for full-term and preterm infants: Meeting normal and exceptional needs. Postgrad Med 1984; 75 (1): 113-22.

[7] Lawson M. Gastro-oesophageal reflux in infants: an evidence-based approach. British J Community Nursing 2003; 8 (7): 296-300.

[8] Nelson SP, Chen EH, Syniar GM, Christoffel KK. Prevalence of Symptoms of Gastroesophageal Reflux During Infancy: A Pediatric Practice-Based Survey. Arch Pediatr Adolesc Med 1997; 151: 569-72. http://dx.doi.org/10.1001/archpedi.1997.02170430035007

[9] Feranchak AP, Orenstein SR, Cohn JF. Behaviors Associated With Onset of Gastroesophageal Reflux Episodes in Infants: Prospective Study Using Split-Screen Video and pH Probe. Clin Pediatr 1994; 33: 654-61. http://dx.doi.org/10.1177/000992289403301104

[10] Condino AA, Sondheimer J, Pan Z, Gralla J, Perry D, O'Connor JA. Evaluation of Infantile Acid and Nonacid Gastroesophageal Reflux Using Combined $\mathrm{pH}$ Monitoring and Impedance Measurement. J Pediatr Gastroenterol Nutr 2006; 42: 16-21.

http://dx.doi.org/10.1097/01.mpg.0000188008.66752.72

[11] Mason DB. Gastroesophageal Reflux in Children: A Guide for the Advanced Practice Nurse. Pediatric Advanced Practice Nursing 2000; 35 (1): 15-36.

[12] Arguin AL, Swartz MK. Gastroesophageal reflux in Infants: $A$ Primary Care Perspective. Pediatr Nurs 2004; 30 (1): 45-51.

[13] Catto-Smith AG. Gastroesophageal reflux in children. Aust Fam Physician 1998; 27 (6): 465-73.

[14] Gilles C. Nonsurgical Management of the Infant With Gastroesophageal Reflux and Respiratory Problems. J Am Acad of Nurse Pract 1991; 3 (1): 11-16.

http://dx.doi.org/10.1111/j.1745-7599.1991.tb01053.x

[15] Jones SP. Relationship Between Apnea and GER: What Nurses Need to Know. Pediatr Nurs 1992; 18 (4): 413-18.

[16] Fox D, Bignall S. Management of Gastrooesophageal Reflux. Pediatr Nurs 1996; 8 (1): 17-20.

[17] Hlusko DL, McMurray J. Gastroesophageal Reflux: treatment and Nursing care. Neonatal Network 1991; 9 (5): 33-36.

[18] Gracey K. Discerning Differences: Gastroesophageal Reflux and Gastroesophageal Reflux Disease in Infants. Adv Neonatal Care 2004; 4 (4): 235-47. http://dx.doi.org/10.1016/j.adnc.2004.05.006

[19] Sterling CE, Jolley SG, Besser AS, Matteson-Kane M. Nursing Responsibility in the Diagnosis, Care, and Treatment of the Child With Gastroesophageal Reflux. J Pedr Nurs 1991; 6 (5): 331-36.

[20] Kelly M. Primary Care Issues for the Healthy Premature Infant. J Pedr Health Care 2006; 20: 293-99. http://dx.doi.org/10.1016/j.pedhc.2006.01.002

[21] Peter CS, Sprodowski N, Ahlborn V, et al. Inter- and Intraobserver Agreement for Gastroesophageal Reflux Detection in Infants Using Multiple Intraluminal Impedance Biol Neonate 2004; 85: 11-14.

[22] Omari TI, Haslam RR, Lundborg P, Davidsson GP. Effect of Omeprazole on Acid in Preterm Infants With Pathological Acid Reflux. J Pediatr Gastroenterol Nutr 2007; 44: 41-44. http://dx.doi.org/10.1097/01.mpg.0000252190.97545.07

[23] Martin P, Bateson P. Measuring Behaviour. An Introductory Guide. Cambridge, University Press; 1986.

[24] Liberati A. et al. The PRISMA Statement for Reporting Systematic Reviews and META-Analyses of Studies That Evaluate Health Care Interventions: Explanation and Elaboration. PLOS Medicine 2009; 7 (7): 1-27.

[25] Evans D, Pearson A. Systematic reviews of qualitative research. Clinical Effectiveness in Nursing 2001; 5: 111-19. http://dx.doi.org/10.1054/cein.2001.0219

[26] Goodman C. Literature Searching and Evidence Interpretation for Assessing Health Care Practices Stockholm: SBU; 1993.

[27] Sandelowski M, Docherty S, Emden C. Qualitative Metasynthesis: Issues and Techniques. Res Nurs Health 1997; 20: 365-71.

http://dx.doi.org/10.1002/(SICl)1098240X(199708)20:4<365::AID-NUR9>3.0.CO;2-E

[28] De Groot L, Hopkins B, Touwen BC. A Method to Assess the Development of Muscle Power in Preterms After Term Age. Neuropediatrics 1992; 23: 172-79.

http://dx.doi.org/10.1055/s-2008-1071336

[29] Waltz CF, Strickland OL, Lenz ER. Measurement in Nursing and Health Research, Third Edition. New York, Springer Publishing Company, Inc.; 2005.

[30] Als H. A Synactive model of Neonatal Behavioral Organisation: Framework for the Assessment of Neurobehavioral Development in the premature Infant and for Support of Infants and Parents in the Neonatal Intensive Care Environment. Physical and Occupational Therapy in Pediatrics 1986; 6: 3-55. http://dx.doi.org/10.1080/J006v06n03 02

[31] Peirce AG. Measurement Instruments. In L.A. Talbot (Ed), Principles and Practice of Nursing Research (ss 292-316). St. Louis, Missouri, Mosby-Year Book, Inc.; 1995.

[32] Bhat RY, Rafferty GF, Hannam S, Greenough A. Acid Gastroesophageal Reflux in Convalescent Preterm Infants: Effect of Posture and Relationship to Apnea. Pediatric Research 2007; 62(5): 620-23. http://dx.doi.org/10.1203/PDR.0b013e3181568123

[33] Corvaglia L, Ferlini M, Rotatori R, et al. Starch thickening of human milk is ineffective in reducing the gastroesophageal reflux in preterm infants: A crossover study using intraluminal impedance. J Pediatr 2006; 148: 265-68. http://dx.doi.org/10.1016/j.jpeds.2005.09.034

[34] Corvaglia L, Rotatori R, Ferlini M, Aceti A, Ancora G, Faldella G. The Effect of Body Positioning on Gastroesophageal Reflux in Premature infants: Evaluation by Combined Impedance and pH Monitoring. J Pediatr 2007; 151 (6): 59196. http://dx.doi.org/10.1016/j.jpeds.2007.06.014

[35] Ewer AK, Durbin GM, Morgan ME, Booth IW. Gastric emptying and gastro- oesophageal reflux in preterm infants. Arc Dis Child 1996; 75: F117-F121.

[36] Khalaf MN, Porat R, Brodsky NL, Bhandari V. Clinical Correlations in Infants in the Neonatal Intensive Care Unit 
With Varying Severity of Gastroesophageal Reflux. J Pediatr Gastroenterol Nutr 2001; 32: 45-49.

http://dx.doi.org/10.1097/00005176-200101000-00014

[37] Dhillon AS, Ewer AK. Diagnosis and management of gastrooesophageal reflux in preterm infants in neonatal intensive care units. Acta Paediatr 2004; 93: 88-93.

http://dx.doi.org/10.1111/j.1651-2227.2004.tb00680.x

[38] Ewer AK, James ME, Tobin, JM. Prone and left lateral positioning reduce gastro-oesophageal reflux in preterm infants. Arc Dis Child 1999; 81: F201- F205.

[39] Jadcherla SR, Gupta A, Fernandez S, et al. Am J Gastroenterol 2008; 103: 720-28.

http://dx.doi.org/10.1111/j.1572-0241.2007.01748.x

[40] Morigeri C, Bhattacharya A, Mukhopadhyay K, Narang A, Mittal, BR. Radionuclide scintigraphy in the evaluation of gastroesophageal reflux in symptomatic and asymptomatic pre-term infants. European Nuclear Medicin Mol Imaging 2008; 35: 1659-1665. http://dx.doi.org/10.1007/s00259-008-0752-y

[41] Akinola E, Rosenkrantz TS, Pappagallo M, Mckay K, Hussain N. Gastroesophageal Reflux in Infants < 32 Weeks Gestational Age at Birth: Lack of Relationship to Chronic Lung Disease. Am J Perinatol 2004; 21 (2): 57-62. http://dx.doi.org/10.1055/s-2004-820512

[42] Snel A, Barnett CP, Cresp TL, et al. Behavior and Gastroesophageal Reflux in the Premature Neonate. J Pediatr Gastroenterol Nutr 2000; 30 (1): 18-21. http://dx.doi.org/10.1097/00005176-200001000-00012

[43] Corvaglia, L, Zama D, Gualdi S, Ferlini M, Aceti A, Faldella, G. Gastroesophageal reflux increases the number of apneas in very preterm infants. Arc Dis Child - Fetal and Neonatal Edition ADC-FNN Online First, published on September 11, 2008 as $10.1136 /$ adc.2008.143198.

[44] Magistá AM, Indrio F, Baldassarre $\mathrm{M}$, et al. Multichannel intraluminal impedance to detect relationship between gastroesophageal reflux and apnoea of prematurity. Digestive and Liver Disease 2007; 39 (3): 216-21. http://dx.doi.org/10.1016/j.dld.2006.12.015

[45] Poblano A, Marquez A, Hernadez G. Apnea in Infants. Indian J Pediatr 2006; 73(12): 1085-88. http://dx.doi.org/10.1007/BF02763050

[46] Peter CS, Sprodowski N, Bohnhorst B, Silny J, Poets CF. Gastroesophageal Reflux and Apnea of Prematurity: No Temporal Relationship. Pediatrics 2002; 109 (1): 8-11. http://dx.doi.org/10.1542/peds.109.1.8

[47] Di Fiore JM, Arko M, Whitehouse M, Kimball A, Martin RJ. Apnea Is Not Prolonged by Acid Gastroesophageal Reflux in Preterm Infants. Pediatrics 2005; 116 (5): 1059-63.

http://dx.doi.org/10.1542/peds.2004-2757
[48] Misra S, Macwan K, Albert V. Transpyloric feeding in gastroesophageal-reflux-associated apnea in premature infants. Acta Paediatr 2007; 96: 1426-29. http://dx.doi.org/10.1111/j.1651-2227.2007.00442.x

[49] Omari TI, Barnett C, Snel A, et al. Mechanisms of gastroesophageal reflux in healthy premature infants. $J$ Pediatr 1998; 133 (5): 1-9. http://dx.doi.org/10.1016/S0022-3476(98)70106-4

[50] López-Alonso M, Moya MJ, Cabo JA, Ribas J, Macías M.C Silny J, et al. Twenty-Four-Hour Esophageal Impedance-pH Monitoring in Healthy Preterm Neonates: Rate and Characteristics of Acid, Weakly Acidic, and Weakly Alkaline Gastroesophageal Reflux. Pediatrics 2006; 118 (2): 299-308. http://dx.doi.org/10.1542/peds.2005-3140

[51] Doshi A, Bernard-Stover L, Kuelbs C, Castillo E, Stucky E. Apparent life-threating event admissions and gastroesophageal reflux disease: the value of hospitalization. Pediatric Emerg Care 2012; 28 (1): 17-21. http://dx.doi.org/10.1097/PEC.0b013e31823ed6f8

[52] Poets CF, Brockmann PE. Myth: gastroesophageal reflux is a pathological entity in the preterm infant. Semin Fetal Neonatal Med 2011; 16 (5): 259-63. http://dx.doi.org/10.1016/j.siny.2011.05.001

[53] Suáres-Morán, E, et al. Influence of central apnea in the preterm newborn with gastroesophageal reflux disease. Cir Cir 2011; 79 (6): 511.

[54] Zimbric G, Bonkowski JL, Jackson WD, Maloney CG, Sirastava, R. Adverse outcomes associated with gastroesophageal reflux disease are rare following an apparent lifethreatening event. J Hosp Med 2012; 24.

[55] Kernberg PF, Chazan SE, Normandin L. The Children's Play Therapy Instrument (CPTI). Description, Development and Reliability Studies. J Psychotherapy Practice and Research 1998; 7 (3): 196-207.

[56] Cranston Andersson G, Radjenovic D, Chiu S-H, Conlon, Lane AE. Development of an Observational Instrument to Measure Mother-Infant Separation Post Birth. J Nurs Meas 2004; 12 (3): 215-34.

http://dx.doi.org/10.1891/jnum.12.3.215

[57] Debillon T, Zupan V, Ravault N, Magny J-F, Dehan M. Development and initial validation of the EDIN scale, a new tool for assessing prolonged pain in preterm infants. Arch Dis Child Fetal Neonatal Ed 2001; 85: F36-F41 http://dx.doi.org/10.1136/fn.85.1.F36

[58] Li HC, Lopez V. Children`s Emotional Manifestation Scale: development and testing. J Clin Nurs 2004; 14: 223-29. http://dx.doi.org/10.1111/j.1365-2702.2004.01031.x

\section{http://dx.doi.org/10.6000/1929-4247.2014.03.02.3}

(C) 2014 Sandberg and Georgsson Öhman; Licensee Lifescience Global.

This is an open access article licensed under the terms of the Creative Commons Attribution Non-Commercial License (http://creativecommons.org/licenses/by-nc/3.0/) which permits unrestricted, non-commercial use, distribution and reproduction in any medium, provided the work is properly cited. 